\title{
North Atlantic winter eddy-driven jet and atmospheric blocking variability in the Community Earth System Model version 1 Large Ensemble simulations
}

\author{
Young-Oh Kwon ${ }^{1}\left[\right.$ ] Alicia Camacho ${ }^{2} \cdot$ Carlos Martinez $^{3} \cdot$ Hyodae Seo $^{1}$
}

Received: 7 April 2017 / Accepted: 8 January 2018 / Published online: 18 January 2018

(c) The Author(s) 2018. This article is an open access publication

\begin{abstract}
The atmospheric jet and blocking distributions, especially in the North Atlantic sector, have been challenging features for a climate model to realistically reproduce. This study examines climatological distributions of winter (December-February) daily jet latitude and blocking in the North Atlantic from the 40-member Community Earth System Model version 1 Large Ensemble (CESM1LE) simulations. This analysis aims at examining whether a broad range of internal climate variability encompassed by a large ensemble of simulations results in an improved representation of the jet latitude distributions and blocking days in CESM1LE. In the historical runs (1951-2005), the daily zonal wind at $850 \mathrm{hPa}$ exhibits three distinct preferred latitudes for the eddy-driven jet position as seen in the reanalysis datasets, which represents a significant improvement from the previous version of the same model. However, the meridional separations between the three jet latitudes are much smaller than those in the reanalyses. In particular, the jet rarely migrates to the observed southernmost position around $37^{\circ} \mathrm{N}$. This leads to the bias in blocking frequency that is too low over Greenland and too high over the Azores. These features are shown to be remarkably stable across the 40 ensemble members with negligible member-to-member spread. This result implies the range of internal variability of winter jet latitude and blocking frequency within the 55-year segment from each ensemble member is comparable to that represented by the full large ensemble. Comparison with 2046-2100 from the RCP8.5 future projection runs suggests that the daily jet position is projected to maintain the same three preferred latitudes, with a slightly higher frequency of occurrence over the central latitude around $50^{\circ} \mathrm{N}$, instead of shifting poleward in the future as documented in some previous studies. In addition, the daily jet speed is projected not to change significantly between 1951-2005 and 2046-2100. On the other hand, the climatological mean jet is projected to become slightly more elongated and stronger on its southern flank, and the blocking frequency over the Azores is projected to decrease.
\end{abstract}

\section{Introduction}

Atmospheric eddy-driven jet and blocking are fundamental dynamical features of the midlatitude weather and climate and are inherently related to each other (Woollings et al. 2008, 2010; Barnes and Hartmann 2010; Davini and

Young-Oh Kwon

yokwon@whoi.edu

1 Physical Oceanography Department, Woods Hole Oceanographic Institution, MS\#21, Woods Hole, MA 02543, USA

2 School of Marine and Atmospheric Sciences, Stony Brook University, Stony Brook 11794, NY, USA

3 Lamont Doherty Earth Observatory, Columbia University, Palisades 10964, NY, USA
Cagnazzo 2013). The jet stream, characterized by currents of strong westerly wind, is probably the most prominent feature of the midlatitude atmospheric circulation. The eddy-driven component of the jet stream, which owes its existence to the convergence of transient eddy momentum and heat fluxes, is dynamically distinct from its subtropical component, which is located at the poleward edge of the thermally driven Hadley Cell. Unlike the subtropical jet, which is an upper level feature, the eddy-driven jet exhibits an equivalent barotropic structure throughout the troposphere down to lower levels (Hoskins et al. 1983; Woollings et al. 2010). This strong zonal flow is sometimes split or diverted meridionally when it encounters an atmospheric blocking, a midlatitude weather phenomenon with a persistent large amplitude anti-cyclone, especially in the North Atlantic (Rex 1950). Blocking is often associated with Rossby wave breaking, a nonlinear process that occurs when the fluctuation of the jet due to 
the presence of a Rossby wave becomes large and unstable (McIntyre and Palmer 1983). Rossby wave breaking is generally characterized by a large-scale overturning of potential vorticity isolines on an upper tropospheric isentropic surface.

In the North Atlantic region, the eddy-driven jet is observed to exhibit three distinct preferred latitudinal positions (Woollings et al. 2010; Davini and Cagnazzo 2013), with abrupt transitions between these positions from 1 day to the next. When the jet is in the southern position $\left(\sim 37^{\circ} \mathrm{N}\right)$, the upper level Rossby wave breaking occurs preferentially on the northern flank of the jet, which results in more frequent blocking over Greenland. On the other hand, the blocking frequency is increased over the Azores when the jet is in its northern position $\left(\sim 55^{\circ} \mathrm{N}\right)$, accompanying increased Rossby wave breaking on its southern flank (Woollings et al. 2008, 2010; Barnes and Hartmann 2010; Michel and Rivière 2011; Davini and Cagnazzo 2013). The synoptic jet and blocking variability is also closely related to the leading modes of low-frequency circulation variability (Woollings et al. 2008, 2010; Davini et al. 2012; Davini and Cagnazzo 2013), i.e., the North Atlantic Oscillation (NAO; Hurrell 1995) and Eastern Atlantic teleconnection pattern (EAP; Barnston and Livezey 1987).

Blocking has long been recognized as one of the most challenging features to realistically simulate in the climate models (D'Andrea et al. 1998; Doblas-Reyes et al. 1998; Scaife et al. 2010; Davini and D'Andrea 2016). Climate models, such as those contributed to the Coupled Model Intercomparison Project Phases 3 and 5 [CMIP3 (Meehl et al. 2007) and CMIP5; (Taylor et al. 2012)], typically underestimate the number of blocking days compared to the reanalysis datasets especially in the high-latitude North Atlantic and Europe between the Greenland and Scandinavia (Anstey et al. 2013; Dunn-Sigouin and Son 2013; Masato et al. 2013). On the other hand, the North Pacific counterpart has experienced substantial improvement in recent simulations (Davini and D'Andrea 2016). Davini and Cagnazzo (2013) pointed out that the biases in the blocking are intimately related to those in the eddy-driven jet locations in the North Atlantic.

There are various ways to define and detect the blocking. They range from 2-dimensional methods (Tibaldi and Moteni 1990; Pelly and Hoskins 2003) to 3-dimensional methods (Barriopedro et al. 2006, 2010; Scherrer et al. 2006; Dunn-Sigouin et al. 2013) and are based on diverse variables, e.g., $500 \mathrm{hPa}$ geopotential height, potential temperature on the $2 \mathrm{PVU}$ potential vorticity surface, $500 \mathrm{hPa}$ zonal wind, potential vorticity, etc. [see Barnes et al. (2012) for a systematic comparison]. While there is some sensitivity of the actual number of blocking days to the choice of definition, the bias mentioned above is known to be relatively insensitive to the various definitions.
Despite the chronic bias in the North Atlantic blocking, there has been some notable incremental improvement in the simulation of the blocking in recent years. Scaife et al. (2010, 2011) found that blocking simulations are improved even in the low-resolution climate models, if the background mean state of the atmosphere were to be realistically constrained in an atmosphere-only simulation by prescribing the observed sea-surface temperature (SST). In addition, the blocking simulations have been shown to be improved in the high-resolution simulations (Matsueda et al. 2009; Scaife et al. 2011; Jung et al. 2012; Berckmans et al. 2013; Schiemann et al. 2017), primarily resulting from the improved representation of the transient eddies and orography (Berckmans et al. 2013; Pithan et al. 2016). As these findings are often based on a few selected climate models, they have yet to be verified in the other climate models or other versions of the same model.

One aspect that has not been fully addressed in the previous studies regarding the biases in the simulated jet and blocking is whether the biases are related to the limited range of the internal variability realized in each of the climate model simulations. The CMIP multi-model ensembles may allow us to explore a wide range of model parameter space. However, they are typically integrated with a limited number (typically less than 10) of ensemble members for each model. Consequently, these simulations may not represent a full range of internal variability within each model climate, and thus the simulated climate may be biased towards a certain state of the potentially undersampled internal variability. While the multi-model ensemble approach based on CMIP simulations are expected to alleviate this issue to some extent, a more systematic approach to address this problem is to use a large (e.g., $n \geq \sim 30$ ) ensemble of simulations using a particular model (Branstator and Selten 2009). In this study, we use the Community Earth System Model version 1 Large Ensemble (CESM1LE) simulations (Kay et al. 2015) to investigate whether the improved representation of a range of the internal climate variability helps to improve the simulation of the blocking statistics in the North Atlantic.

Section 2 will describe the CESM1LE, additional auxiliary simulations, and reanalysis datasets as well as the definition of the blocking, eddy-driven jet latitude, and NAO used in our study. The comparison between the CESM1LE and the reanalysis data in terms of the winter daily eddydriven jet distribution and the number of blocking days will be presented in Sect. 3. In addition, comparison of the winter daily jet and blocking between the twentieth century historical runs and the twenty-first century future projection runs of the CESM1LE will be made to infer projected changes in latitude and strength of the eddy-driven jet and the frequency of the blocking in the North Atlantic. Finally, a brief summary and discussion will follow in Sect. 4. 


\section{Model simulations, observations and definitions}

\subsection{Community Earth System Model version 1 Large Ensemble simulations}

The Community Earth System Model version 1 (CESM1) is a fully coupled global climate model with atmosphere, ocean, land and sea-ice components coupled through a coupler. The atmosphere component model is the Community Atmospheric Model version 5 (CAM5; Park et al. 2014) with the finite volume dynamical core with $\sim 1^{\circ}$ horizontal resolution and 30 vertical levels. The ocean component is the Parallel Ocean Program version 2 (POP 2; Danabasoglu et al. 2012) with the horizontal resolution at $1.125^{\circ}$ in longitude and $0.27-0.54^{\circ}$ in latitude and 60 vertical levels. The land and sea-ice components are the Community Land Model version 4 (CLM4; Lawrence et al. 2012) and the Sea Ice Model version 4 (CICE4; Holland et al. 2012) with the same horizontal resolutions as the atmosphere and ocean components, respectively.

The CESM1 Large Ensemble (CESM1LE) is an ensemble simulation with 40 members, which slightly differ only in the initial condition for the air temperature field (Kay et al. 2015). All 40 members span 1920-2100 (while only the first member started in 1850) with the common external forcing specified following the CMIP5 protocol, i.e., the historical forcing for 1920-2005 (Lamarque et al. 2010) and the Representative Concentration Pathway 8.5 (RCP8.5) forcing for 2006-2100 (Meinshausen et al. 2011). The last 55 years of the historical forcing period, 1951-2005, is used as the primary analysis period for this study, which is compared with two different reanalyses for the same period. In addition, the last 55 years of the RCP8.5 forcing period, 2046-2100, is compared with the 1951-2005 period to examine the projected future change.

\subsection{Auxiliary simulations}

One ensemble member (b40.20th.track1.1 deg.008) from the twentieth century hindcast simulation of the Community Climate System Model version 4 (CCSM4; Gent et al. 2011), which is a part of the CMIP5 simulations, is used to calculate the daily jet latitude distribution and compare to that from the CESM1LE. This CCSM4 simulation used the CAM4 (Neale et al. 2013) for the atmospheric component while the ocean, sea-ice and land components were identical to those of the CESM1LE. In addition, the horizontal resolutions in all four components are identical to those of the CESM1LE. The CCSM4 has been shown to exhibit common blocking and eddy-driven jet biases described in the introduction (Neale et al. 2013; Davini and Cagnazzo 2013).

In addition, a set of three CAM5 atmospheric-only simulations with differing horizontal and vertical resolutions is used to calculate the winter mean number of blocking days. All three simulations are based on CAM5 with prescribed SST and sea-ice boundary conditions, but their configurations are slightly different since they are not part of the same experiment. The first simulation is based on the finite volume dynamical core CAM5 with $1^{\circ}$ horizontal resolution, 30 vertical levels and specified observed historical SST globally for 1880-2005. The output files are available through the CESM Climate Variability and Change Working Group (http://www.cesm.ucar.edu/working_groups/ $\mathrm{CVC} /$ ). The second simulation similarly used the specified observed historical SST and $1^{\circ}$ horizontal resolution but is based on the spectral element dynamical core CAM5 with the 46 vertical levels, instead of the standard 30 levels, which better resolves the stratospheric process (Richter et al. 2015). The simulation was integrated from 1952 to 2014 . The third simulation is based on the $0.25^{\circ}$ finite volume dynamical core CAM5 with 30 vertical levels and specified observed climatological mean SST. This simulation is the control simulation of the experiment described in Smirnov et al. (2015), which consists of 25 members of 5-month winter (November-March) runs with different initial conditions from the observed November 1st conditions in 25 different years.

\subsection{Reanalysis datasets}

Two different reanalysis datasets are analyzed in parallel with the CESM1LE simulations for the 1951-2005 period. The National Centers for Environmental Prediction (NCEP)-National Center for Atmospheric Research (NCAR) reanalysis (Kalnay et al. 1996; Kistler et al. 2001) is primarily used to compare with the CESM1LE simulations. In addition, the NOAA Twentieth Century Reanalysis (20CR; Compo et al. 2006, 2011) are also analyzed. The 20CR provides a 56-member ensemble as well as the ensemble mean fields. The North Atlantic blocking and jet statistics in 20CR exhibit extremely small ensemble spread for the study period (after the 1940s, not shown), which indicates the assimilated sea-level pressure data and the prescribed SST and sea-ice concentration boundary conditions predominantly constrain the reanalysis field. More importantly, the results from the $20 \mathrm{CR}$ are very similar to those from the NCEP-NCAR reanalysis, thus only the latter is presented in this paper. 


\subsection{Definitions for the jet latitude and blocking}

The daily jet latitude in the North Atlantic is defined based on the zonal wind at $850 \mathrm{hPa}$ following Woollings et al. (2010) and Davini and Cagnazzo (2013). The daily zonal wind at $850 \mathrm{hPa}$ is averaged zonally over $75^{\circ} \mathrm{W}-15^{\circ} \mathrm{E}$ and temporally smoothed with a 5-day running mean. Then, the latitude of the maximum amplitude is identified as the jet latitude for each day. The daily jet latitude is calculated using the native latitude grids of each dataset without any spatial interpolation. Some previous studies used a narrower zonal sector, e.g. $0-60^{\circ} \mathrm{W}$ (Woollings et al. 2010), for the jet latitude calculation from reanalyses. We use $75^{\circ} \mathrm{W}-15^{\circ} \mathrm{E}$ here instead given that the simulated jet is too strong and extends farther downstream, a typical bias in the CMIP5 models (Davini and Cagnazzo 2013). The sensitivity of the jet latitude distribution on the choice of the zonal range and other parameters is shown to be reasonably small in Appendix.

The blocking index is defined based on the meridional gradient of the daily geopotential height at $500 \mathrm{hPa}$ (Z500) following Scherrer et al. (2006), which is a 2-dimensional extension of 1-dimensional definition by Tibaldi and Molteni (1990). On each day, at a given location, the meridional gradients are calculated against the locations $\sim 15^{\circ}$ north and south, respectively:

$\Delta Z 500_{S}=\frac{Z 500\left(x_{0}, y_{0}\right)-Z 500\left(x_{0}, y_{S}\right)}{y_{0}-y_{S}}$

$\Delta Z 500_{N}=\frac{Z 500\left(x_{0}, y_{N}\right)-Z 500\left(x_{0}, y_{0}\right)}{y_{N}-y_{0}}$

where, $x_{0}$ and $y_{0}$ are the reference longitude and latitude, respectively, while $y_{S}=y_{0}-\Delta y$ and $y_{N}=y_{0}+\Delta y$. Note that these meridional gradients are calculated using the native latitude grid of each dataset, and thus $\Delta y$ is $15^{\circ}$ for NCEP-NCAR reanalysis while it is $15.08^{\circ}$ for CESM1LE. When there is a blocking, we expect the gradient to the south to be reversed $\left(\Delta Z 500_{S}>0\right)$ (Lejanäs and Økland 1983). We impose additional criterion for the gradient to the north $\left(\Delta Z 500_{N}<-10 \mathrm{~m} /{ }^{\circ}\right.$ latitude) to ensure a westerly flow to the north of the blocking as the jet being split around the blocking (Tibaldi and Moteni 1990; Barnes et al. 2012). Once these two criteria are met at any given space and time, an instantaneous blocking is identified. If five or more consecutive days of instantaneous blocking are found at a location, then those days are identified as the blocking days. No additional criterion to account for spatial and temporal coherences (e.g. Barnes et al. 2012) is considered.
The daily NAO index time series is calculated based on the projection of the daily Z500 field on the winter (December-February) NAO spatial pattern. The winter NAO spatial pattern is defined as the spatial pattern for the leading Empirical Orthogonal Function (EOF) of the winter mean Z500 in the North Atlantic. Subsequently, the positive and negative NAO days are defined as the days with daily NAO index time series value greater or smaller than the one standard deviation, respectively. All the analyses are conducted for December-February.

\section{Results}

\subsection{Historical simulations: 1951-2005}

First, we examine the ensemble averaged climatological mean winter zonal wind at $200 \mathrm{hPa}$ and the number of blocking days in 1951-2005 from the historical simulations of CESM1LE to assess their realism against the reanalysis datasets for the same time period (Fig. 1). We can readily see the biases in jet position and strength are intimately coupled with the bias in blocking frequency. In the CESM1LE, the zonal jet is too elongated and strong, extending to western Europe, which seems to be closely linked with the fact that the blocking is lacking over the British Isles and the North Sea. Furthermore, the blocking is overly concentrated on the southern flank of the jet and almost absent over Greenland in the CESM1LE compared to the NCEP-NCAR reanalysis.

Next, the latitudinal distribution of the daily eddy-driven jet is examined. In winter, the eddy-driven jet exhibits three distinct preferred latitudes in the North Atlantic with a rather clear separation among them (Fig. 2a; Woollings et al. 2010). These different jet positions are intimately associated with the leading modes of variability, i.e., the NAO and EAP (Woollings et al. 2010; Davini and Cagnazzo 2013). For example, the southern jet position $\left(\sim 38^{\circ} \mathrm{N}\right)$ occurs preferentially during the negative NAO days, while the northern position $\left(\sim 58^{\circ} \mathrm{N}\right)$ is favored with the positive NAO days (Fig. 2a). While this highlights the relationship between the jet position and NAO, it is also clear that only a part of the jet position variability is associated with NAO (Woollings et al. 2010).

For the CESM1LE (Figs. 2b, 3), in addition to all 40 members, one representative member (member \#3) is highlighted (with the thick lines in Fig. 2b) to aid the visual comparison with the reanalysis. The member \#3 is chosen because its jet latitude histogram has the smallest RMS difference against the ensemble mean of the jet latitude histograms (Fig. 2b). The CESM1LE reproduces the distinct preferred latitudes for daily jet distribution (Fig. 2b), which 
Fig. 1 Climatological winter (December-February) mean zonal wind at $200 \mathrm{hPa}$ (contours) and the number of blocking days (shadings) for 1951-2005 from a the NCEPNCAR reanalysis and $\mathbf{b}$ the CESM1LE. The CESM1LE values are the ensemble averages
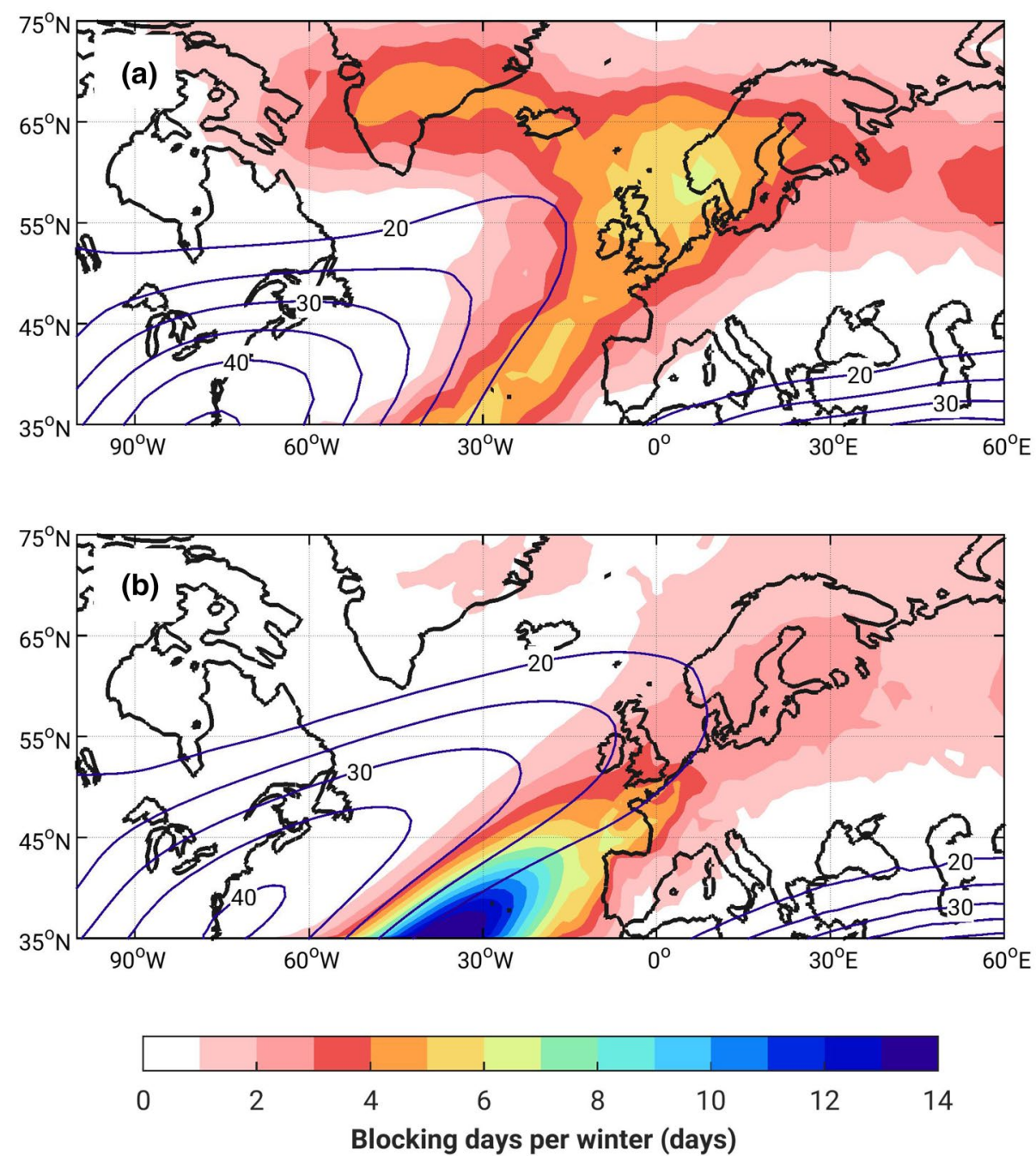

is an improvement from the monopole Gaussian-like distribution simulated by its predecessor, the CCSM4 (dashed green line in the Fig. 2b; Davini and Cagnazzo 2013). However, the CESM1LE still exhibits significant biases. Compared to the reanalysis (Fig. 2a), the distances between the three preferred latitudes (i.e. the peaks in the histogram) are too small, and the central and southern jet positions are too northerly. In addition, there is a fourth much smaller peak around $38^{\circ} \mathrm{N}$ (hereafter the southernmost peak), which corresponds to the actual southern jet position in the reanalysis. The jet is concentrated overly around the central jet position $\left(\sim 50^{\circ} \mathrm{N}\right)$ in CESM1LE (Fig. 2b) compared to the reanalysis (Fig. 2a). Note that the reanalysis also shows the largest peak in the central jet position, if the zonal average for the zonal wind were limited to $0-60^{\circ} \mathrm{W}$ (Woollings et al. 2010). The result is extremely robust across the all the 40 ensemble members (Figs. 2b, 3).

We now examine the relationship between the eddydriven jet latitude distribution and the winter blocking occurrence. As previous studies suggested, the latitude of jet and the location of blocking are closely related (Woollings et al. 2008, 2010; Barnes and Hartmann 2010; Davini and Cagnazzo 2013). In the reanalysis, the blocking is mostly found over Greenland and Scandinavia to the north of the jet when the jet is in the southerly position (Fig. 4e). On the other hand, the blocking occurs from the Azores to the British Isles on the southern flank of the jet with the northerly jet position (Fig. 4a). Quantitatively, 10-20\% of days belonging to each of the jet latitude cases exhibit blocking in the corresponding blocking locations. In contrast, blocking in the CESM1LE is found to the south of the jet in all three primary jet positions, thus significantly underestimating Greenland or Scandinavia blocking occurrences (Fig. 5a, c, e). This is attributed to the fact that the simulated jet does not move to subtropical latitudes frequently enough to result in the wave breaking on the northern flank of the jet (Fig. 3). 

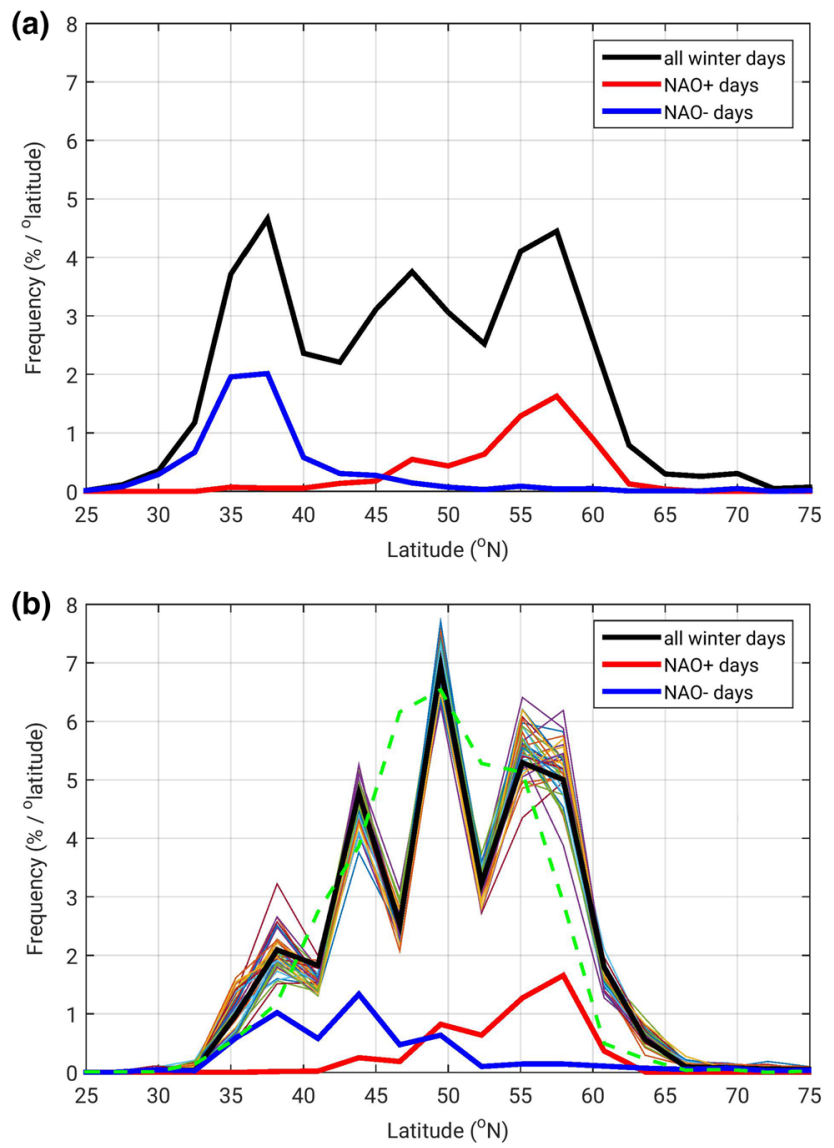

Fig. 2 The histograms of winter (December-February) daily jet latitude in the North Atlantic $\left(75^{\circ} \mathrm{W}-15^{\circ} \mathrm{E}\right)$ for $1951-2005$ from a the NCEP-NCAR reanalysis and $\mathbf{b}$ all 40 ensemble members of the CESM1LE (solid lines) and one member from CCSM4 (green dashed line). The CESM1LE ensemble member \#3 is emphasized with the thick black, red, blue curves, while all the other members are plotted with thin color lines. The thick black and thin colored curves are for the all winter days, while the thick red (blue) curves are for only the positive (negative) NAO days. Note that the histogram is constructed based on the original meridional resolution of each dataset. Therefore, the bin sizes are $2.5^{\circ}$ for the NCEP-NCAR reanalysis and $2.83^{\circ}$ for the CESM1LE and CCSM4. To aid a comparison between the two panels, they are further normalized so that the integral below each curve is $100 \%$, except for the NAO day curves

Even in CESM1LE, however, when the jet occasionally occupies the observed southern jet latitude around $38^{\circ} \mathrm{N}$ (the southernmost peak in CESM1LE), the blocking does occur over Greenland and Scandinavia (Fig. 5g). However, the frequency of blocking occurrence near Greenland and Scandinavia is still only about one-half of the blocking occurrence when the observed jet is in the southern jet position, which suggests there are additional factor(s) inhibiting the cyclonic Rossby wave breaking and blocking on the northern flank of the jet even when the jet is positioned southerly enough. One potential factor to be considered is the effect of the too strong jet in CESM1LE.

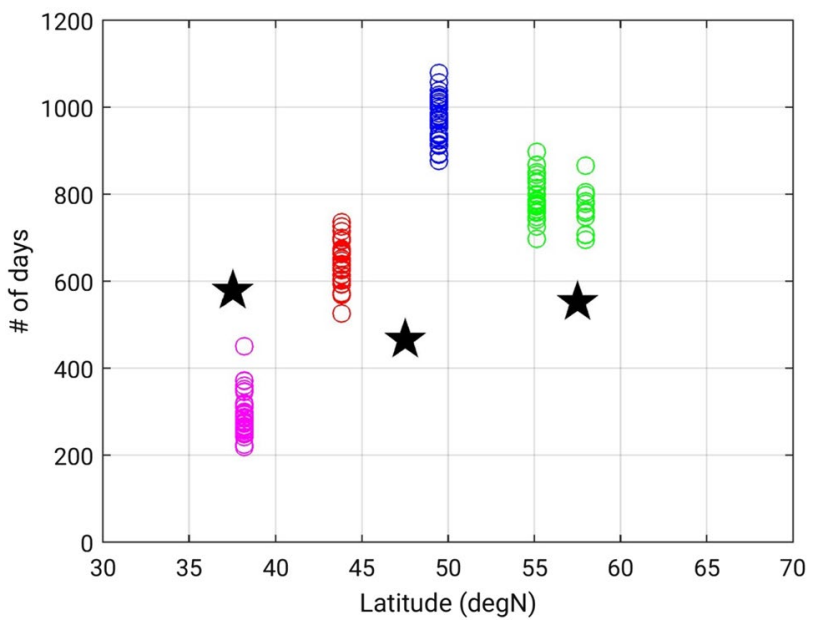

Fig. 3 The locations of the four distinct peaks in the daily jet latitude histograms of all 40 CESM1LE ensemble members, i.e., each member contributes to one dot for each color. The green, blue, red, and magenta dots denote the peaks associated for the northern, central, southern, and southernmost jet position, respectively. The black stars indicate the locations of the three peaks from the histogram of the NCEP-NCAR reanalysis shown in the Fig. 2a

The southernmost jet in CESM1LE is about $5 \mathrm{~m} / \mathrm{s}$ stronger than the southern jet in the reanalysis (Figs. $4 \mathrm{e}$ vs. $5 \mathrm{~g}$ ). A stronger jet may increase the tendency for the Rossby waves to be trapped within the jet by enhancing the wave refraction toward the jet core, which would limit the wave breaking and subsequent blocking (Hoskins and Ambrizzi 1993; Barnes and Hartmann 2011).

The CESM1LE southernmost jet latitude is associated with the negative NAO days as in the reanalysis. While the histograms for the positive and negative NAO days (red and blue histograms in Fig. 2b, respectively) exhibit some correlation with the jet position, the relationship in the CESM1LE is not as strong as in the reanalysis. This, however, is still an improvement from its predecessor CCSM4 (Davini and Cagnazzo 2013). The positive NAO days in the CESM1LE are split into the central and northern jet positions, while the negative NAO days exhibit even broader distribution with the peak in both the southern and southernmost jet positions.

This weaker relationship between the circulation and jet latitude is also apparent from the Z500 composites for each of the jet positions (Figs. 4 vs. 5 right columns). The Z500 composite from the reanalysis for the southern jet position shows the typical NAO negative phase, while the northern jet position days exhibit a north-south dipole similar to the NAO positive phase but displaced slightly to the north, thus a mixture between the positive NAO and negative EAP (Fig. 4b, f; Woollings et al. 2010). The central jet position in the reanalysis has the negative northern pole positioned near the center of positive EAP, however, with 
Fig. 4 Composite maps of the NCEP-NCAR reanalysis a, $\mathbf{c}$, e zonal wind at $200 \mathrm{hPa}$ (contours) and days with blocking as the percentage of total number of days in each composite map (shades), and b, d, f geopotential height anomalies at $500 \mathrm{hPa}$ with red (blue) indicating the positive (negative) anomalies. The composites are based on the days when the jet is found at one of the three preferred latitudes, i.e. a, $\mathbf{b}$ the northern jet latitude, $\mathbf{c}, \mathbf{d}$ the central jet latitude, and $\mathbf{e}, \mathbf{f}$ the southern jet latitude. Only one latitude grid for each jet location is used as shown in the Fig. 3 with the stars. The contour intervals are $5 \mathrm{~m} / \mathrm{s}$ and $10 \mathrm{~m}$, respectively
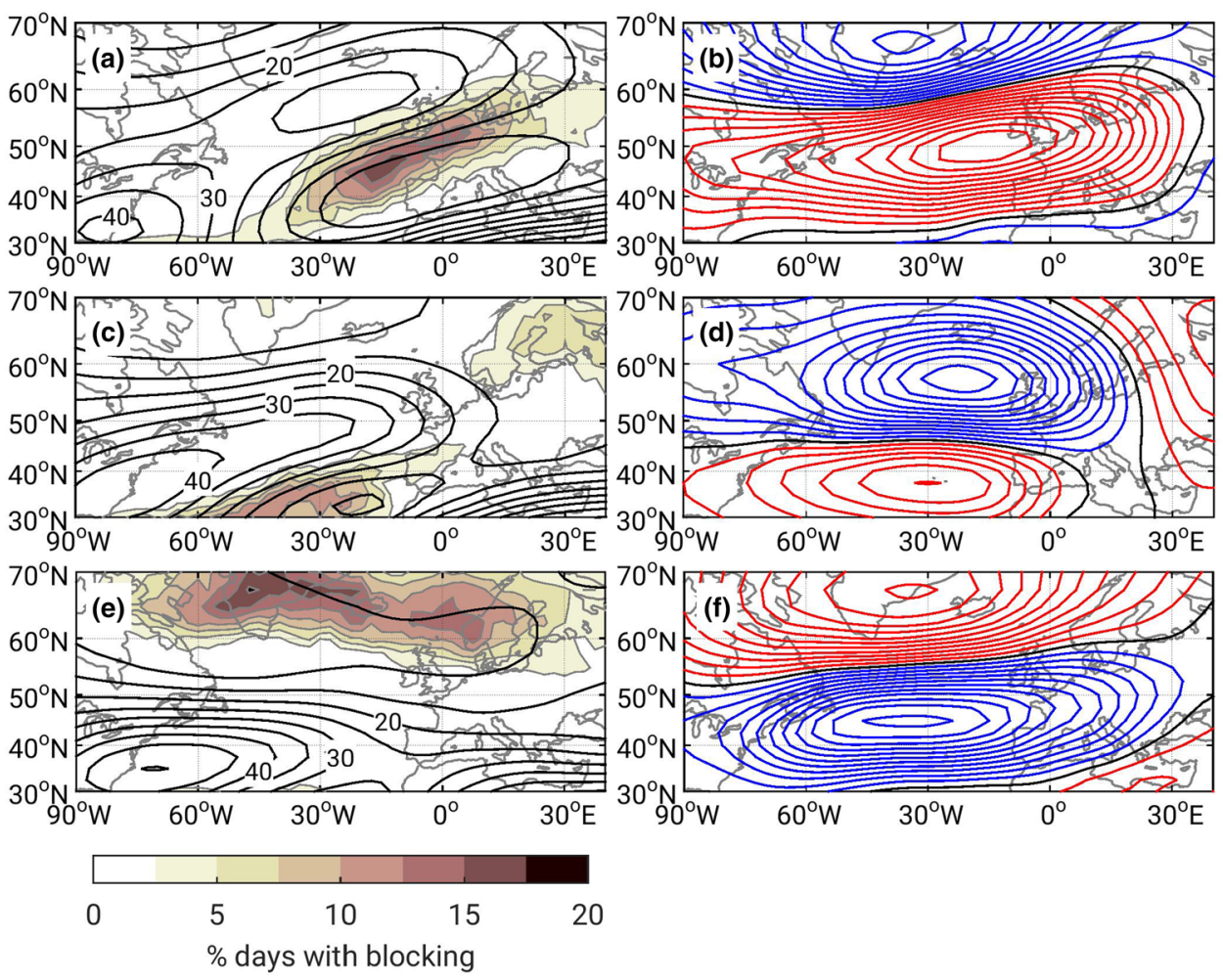

an opposite pole to the south with a comparable strength as shown in some of the previous works for the EAP (e.g. Lim 2015). In the CESM1LE, the Z500 composite for the southern jet days projects strongly on the positive EAP, instead of the negative NAO (Fig. 5f). Therefore, the simulated southern jet behaves like the central jet in the reanalysis by accompanying the positive EAP-like circulation pattern and the blocking near the Azores. On the other hand, the CESM1LE Z500 composite for the northern jet days is fairly realistic except for the weaker amplitudes (Fig. 5b). The CESM1LE central jet days exhibit a dipole anomaly in Z500. The dipole anomaly is tilted in southwest-northeast direction compared to those in the reanalysis, which makes it similar to the Scandinavia teleconnection pattern (Bueh and Nakamura 2007; Lim 2015). This tilting of the Z500 anomalies for the central jet days in CESM1LE is consistent with the central jet being too strong and extending too far downstream in these simulations (Figs. $4 \mathrm{~d}$ vs. $5 d)$. Finally, when the simulated jet is in the southernmost position, the associated circulation pattern becomes similar to negative NAO as in the southern position of the jet in the reanalysis.

The bias in the distribution of blocking can result in the bias in the circulation not only for the time mean but also for its variability. Figure 6 shows the distribution of winter daily Z500 averaged over a region around Greenland $\left(60^{\circ}-72^{\circ} \mathrm{N}, 20^{\circ}-60^{\circ} \mathrm{W}\right)$. The distribution from the reanalysis (thick blue curve) exhibits a skewed distribution with a long tail towards the higher Z500 values. As the blocking is by definition a high-pressure system, the days with higher Z500 values are also the days with blocking present in the same region as expected (thick red curve). For example, $77 \%$ of the days with Z500 greater $5400 \mathrm{~m}$ are also the days with blocking. In addition, most of the days with the higher Z500 values are also negative NAO days (thick green curve), e.g. $89 \%$ of the days with the geopotential heights greater $5400 \mathrm{~m}$.

In CESM1LE, all 40 ensemble members exhibit less skewed Z500 distributions, which are also biased toward the overall smaller Z500 values (thin cyan curves), compared to the reanalysis. In particular, the absence of the blocking days over Greenland (thin pink curves) contributes to a significant reduction of the high Z500 values in CESM1LE. For example, the number of days with the heights greater than $5400 \mathrm{~m}$ is 410 days in the reanalysis while only 88-214 days for the CESM1LE. Correspondingly, the Z500 values for the negative NAO days (thin green curves) are smaller than those in the reanalysis. Nevertheless, the overall number of negative NAO days in CESM1LE is similar to that in the reanalysis, as the NAO is defined based on the leading EOF, of which the physical interpretation could be unrealistic (Davini and Cagnazzo 2013). 
Fig. 5 As in the Fig. 4, but for the CESM1LE ensemble member \#3. The bottom two panels $\mathbf{g}, \mathbf{h}$ are for the southernmost jet latitude
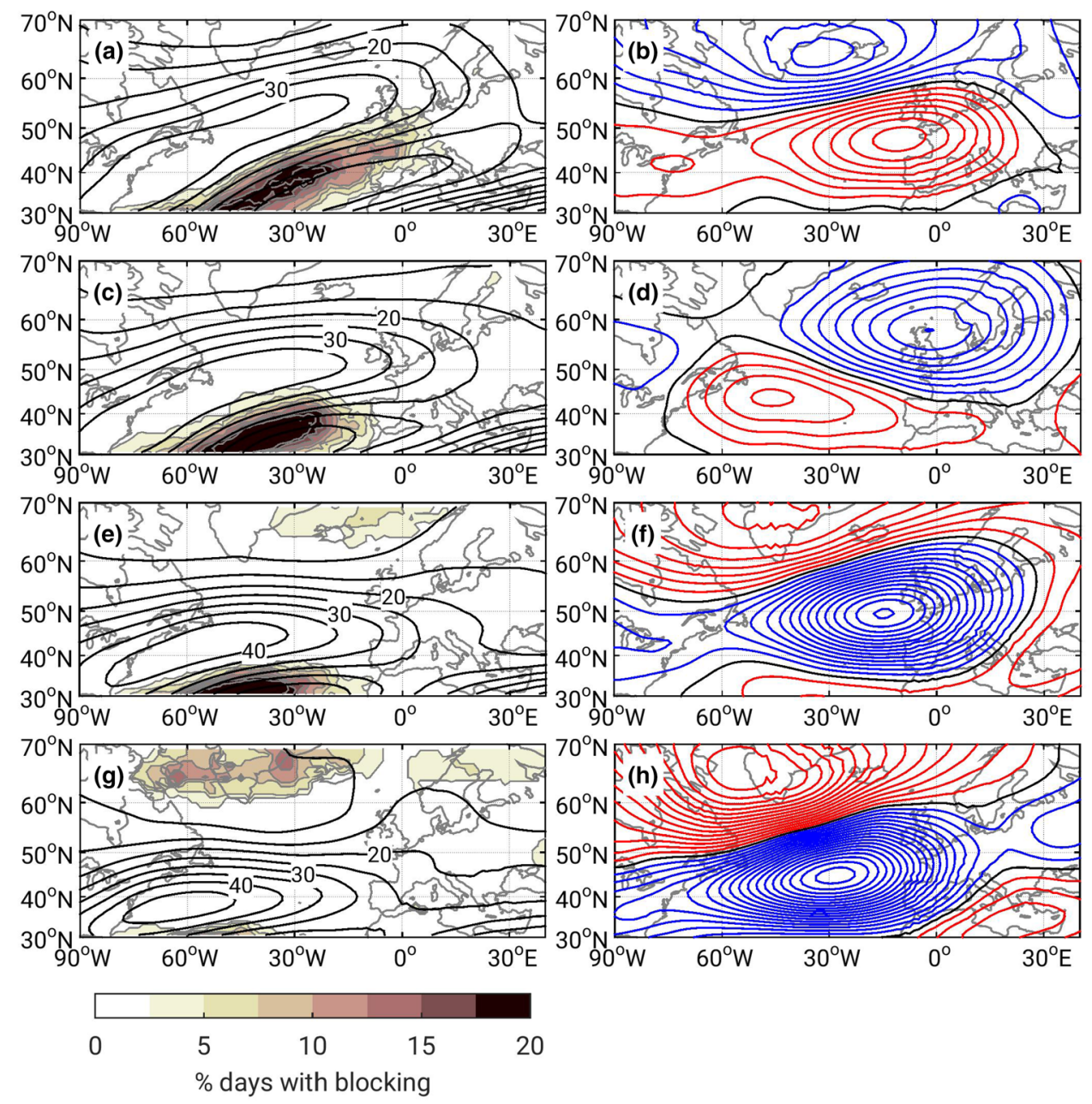

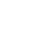

\subsection{Future projection: 2046-2100 vs. 1951-2005}

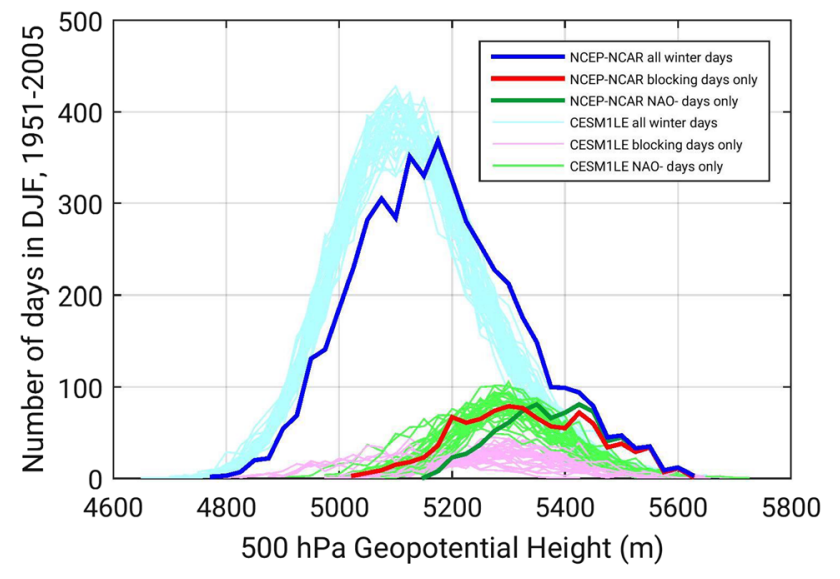

Fig. 6 Histograms of the winter (December-February, 1951-2005) daily $500 \mathrm{hPa}$ geopotential height averaged over the Greenland region $\left(60^{\circ}-72^{\circ} \mathrm{N}, 20^{\circ}-60^{\circ} \mathrm{W}\right)$ from the NCEP-NCAR reanalysis (thicker lines) and each ensemble member of the CESM1LE (lighter lines). Blue/cyan lines are based on all the winter days and red/pink lines are for only the days with the blocking in the region. Green lines are for only the negative NAO days
Given the distribution of the winter eddy-driven jet and blocking days from the last 55 years of the historical run (1951-2005) discussed in the previous section, the corresponding changes in the future for the second half of the twenty-first century (2046-2100) are examined briefly in this section. It should be noted that the result should be interpreted with caution given the biased jet and blocking simulation in the historical run.

A histogram of the winter daily jet latitude for 2046-2100 from the CESM1LE member \#3 is shown in the Fig. 7a (red curve) along with the corresponding histogram for 1951-2005 (black curve in Fig. 7a). As noted above, the member \#3 represents the all 40 members very well (Fig. 7b). These histograms show that the overall structure of the future jet latitude distribution is very similar to that from the historical run, with three primary peaks and one additional southernmost peak at the exactly same latitudes. The only difference seems to be that the future jet latitude distribution is slightly more concentrated toward the central jet position. This characterization from one ensemble 

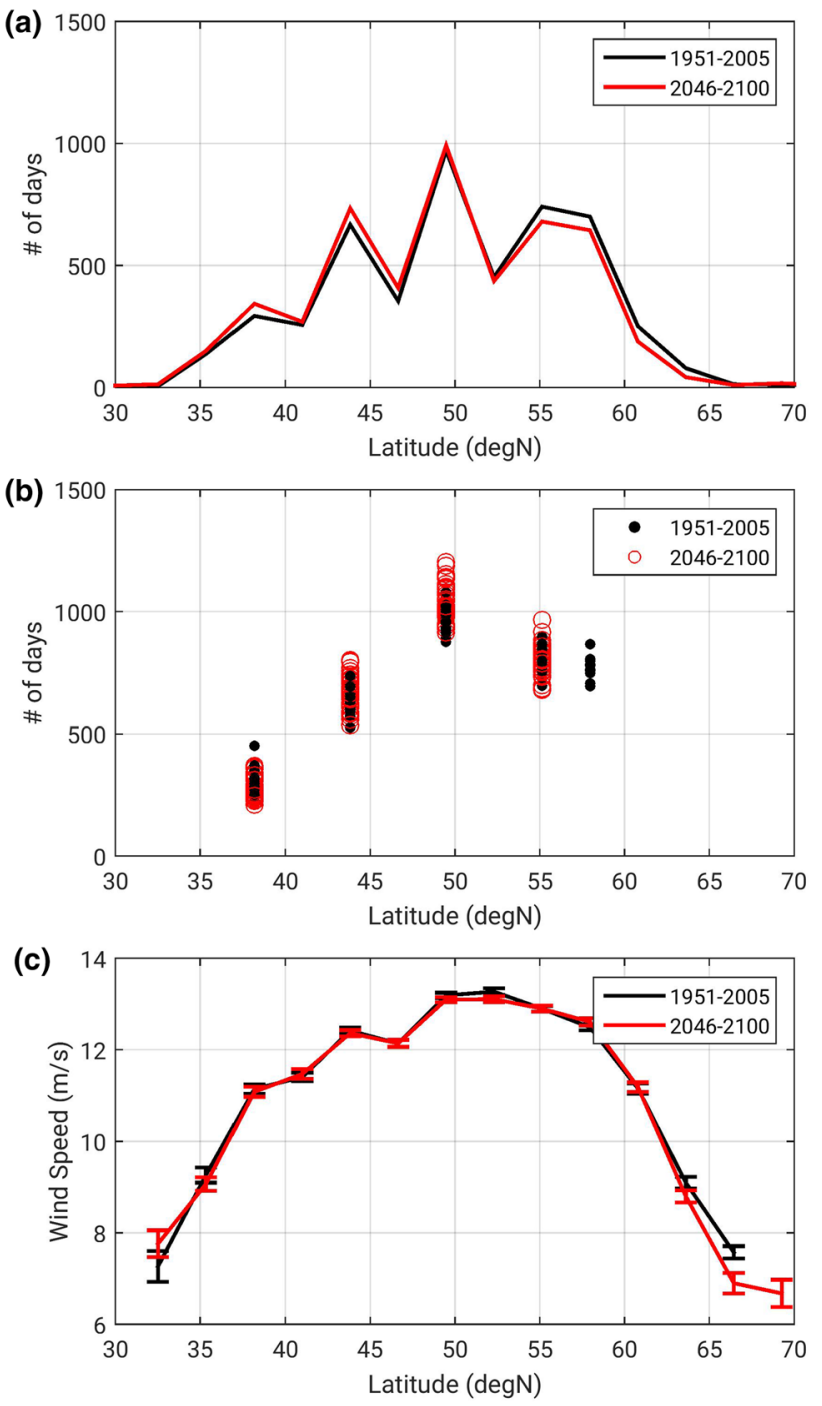

Fig. 7 a Histograms of the daily jet latitude from the CESM1LE ensemble member \#3 for 1951-2005 (black) and 2046-2100 (red). b As in the Fig. 3 but for 1951-2005 (black) and 2046-2100 (red). c The ensemble mean daily jet amplitude from the all 40 members of CESM1LE for 1951-2005 (black) and 2046-2100 (red). The error bars indicate $95 \%$ confidence interval based on the standard deviation of the ensemble spread

member is again consistent across the all 40 members (Fig. 7b). The northern jet is projected to be even more concentrated, i.e., the northern jet positions from the all 40 members are found in one latitude bin in the future projection as opposed to the two latitude bins in the historical run. Furthermore, the histograms from the all 40 members show $~ 8 \%$ more days in the central jet position $(2-8 \%$ for three primary jet positions together) and $\sim 5 \%$ fewer days in the southernmost jet position in the future projection. Therefore, the blocking over Greenland and Scandinavia would become even less frequent in the second half of the twenty-first century in the CESM1LE. Indeed, the already too infrequent blocking over Greenland is further reduced in the projected future blocking days (Fig. 8a). An even larger $(\sim 30 \%)$ decrease in the blocking days is projected over the Azores.

The reason for this decrease is not immediately obvious given the slight projected increase in the central and southern jet frequencies. Furthermore, the projected jet strength is not statistically significantly different from the 1951-2005 distribution in all latitudes (Fig. 7c). However, the climatological mean jet based on the zonal wind at $200 \mathrm{hPa}$ is projected to be slightly more elongated and stronger on the southern flank (Fig. 8b).

\section{Summary and discussions}

The distribution of the winter (December-February) daily eddy-driven jet, blocking, and circulation anomalies in the North Atlantic for 1951-2005 is investigated from the 40 ensemble members of the Community Earth System Model version 1 Large Ensemble (CESM1LE) simulations and compared against two atmospheric reanalysis datasets. The distribution of the eddy-driven jet in CESM1LE simulations shows the three distinct preferred latitudes and one additional secondary preferred location, which is an improvement from its predecessor (CCSM4). However, the separations between the latitudes of the three primary peaks in the jet latitude histogram are too small compared to those in the reanalysis. In particular, the jet does not spend enough time in the observed southern jet position near $38^{\circ} \mathrm{N}$, thereby the model underestimates the blocking frequency over Greenland. This bias in the jet and blocking distribution results in a bias not only in the mean blocking frequency (Fig. 1) but also a bias in the variability of the geopotential height (Fig. 6), thus affecting the internal variability of the model (Davini et al. 2012; Davini and Cagnazzo 2013).

The biases in the jet and blocking distributions are remarkably similar in all 40 ensemble members of CESM1LE. This implies that the range of internal variability of these two variables in each of the 55-year long ensemble member is comparable to that represented by the full large ensemble, while the time evolution of these variables show a spread among the ensemble members (Branstator and Selten 2009). To further confirm this interpretation, we calculate the histogram for the two different kinds of standard deviations for the number of days when the jet is at the latitude of its central jet peak in each winter (Fig. 9a). First, the interannual standard deviation is calculated from each time series of 55 winters for each ensemble member, and the histogram of 40 interannual standard deviations is shown with the blue 
Fig. 8 Ensemble average winter (December-February) mean a number of blocking days and $\mathbf{b} 200 \mathrm{hPa}$ zonal wind for 2046-2100 from the CESM1LE (shadings). The red and blue contours are for the difference from 1951 to 2005 ensemble average. The positive (negative) anomalies with red (blue) contours indicate projected increase (decrease) in the future
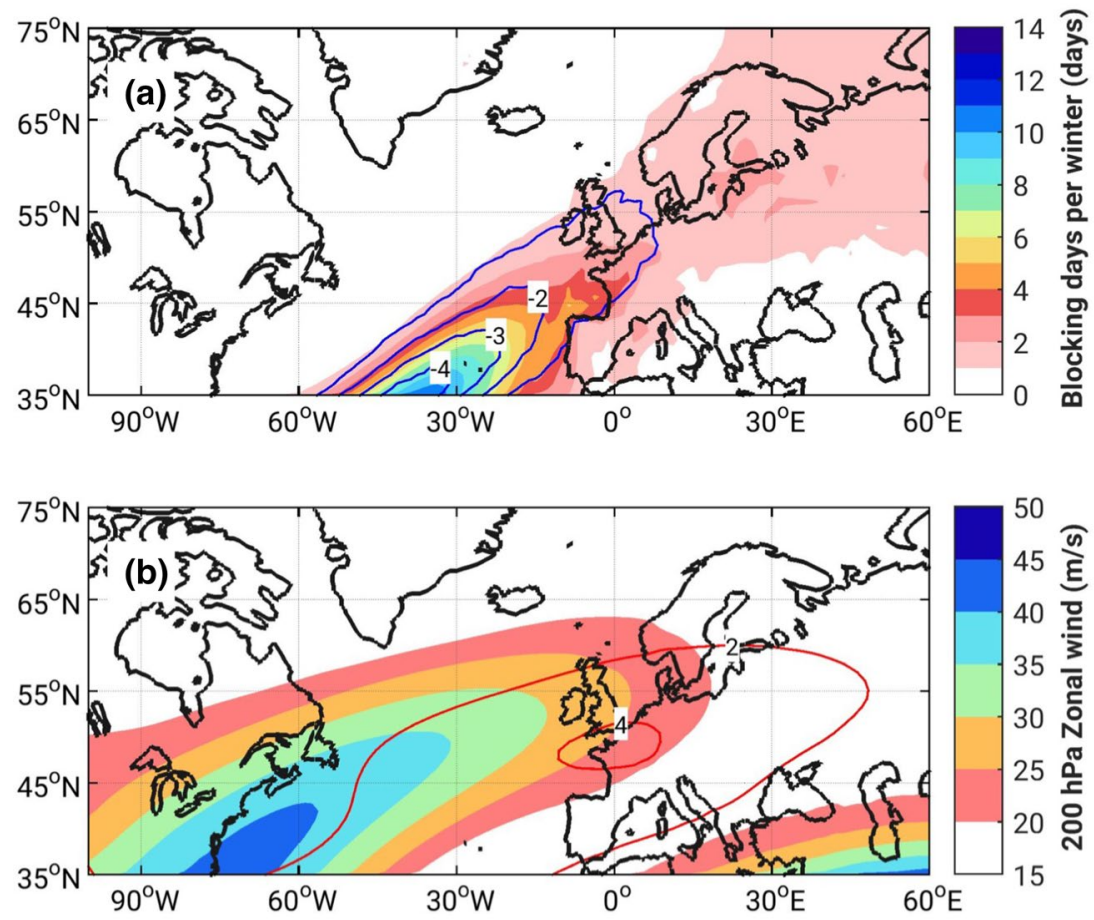

bars. The second histogram (the white bars with red edges) is constructed based on the standard deviations of the same variable from each winter across the 40 ensemble members. Therefore, the second histogram exhibits the distribution of the internal variability. The distributions of interannual and internal variability as represented by the two histograms are comparable, although the range of the internal variability is slightly larger. Furthermore, a consistent result is found when the histograms are constructed for the standard deviations of the number of blocking days over the Azores in each winter (Fig. 9b). If a longer length of the record is used, the range of the interannual variability could be larger and become even more comparable to the range of internal variability. These results, of course, suggest that more than a single realization is needed to correctly sample the natural variability. It is important to understand the ensemble size required to properly sample the full range of the internal variability, which would depend on the variable and region of interest.

The bias in the mean distribution of blocking has been a persistent problem in the climate models as discussed in the introduction. Some studies suggested that an improved blocking distribution may be obtained with a realistic SST boundary condition (Scaife et al. 2010), higher atmospheric resolution (Scaife et al. 2011; Schiemann et al. 2017), or a better representation of the stratosphere (Anstey et al. 2013). Therefore, we have briefly examined the mean winter blocking distributions from the various available CESM1 simulations in fully coupled configuration as well as the atmosphere-only (CAM5) configuration (Fig. 10). Note that these simulations do not use exactly the same version or configuration of the model since they are not a collection from a single systematic sensitivity experiment (Sect. 2.2). Nevertheless, the results highlight the robustness of the bias in the blocking distribution, i.e., not enough blocking days over Greenland/Scandinavia and too many near the Azores, across the different model configurations, and thus imply associated biases in the jet and circulation. However, the simulations with the higher horizontal resolution (Fig. 10d) or better representation of the stratosphere (Fig. 10c) hint at some improvement.

The RCP8.5 future projection simulations exhibit more or less the same daily jet latitude distribution as the historical simulation in the CESM1LE, with the exception of slightly more concentration towards the central jet latitude. This finding may not be consistent with the previous studies suggesting a poleward expansion of Hadley Cell and storm tracks as a response to the anthropogenic global warming (Yin 2005; Lu et al. 2007). On the other hand, some studies suggested that the North Atlantic storm tracks and the eddy-driven jet would mainly intensify and extend further eastward instead of shifting poleward in contrast to the other regions (Pinto et al. 2007; Ulbrich et al. 2008), as also shown in our study with the climatological mean jet at $200 \mathrm{hPa}$. In particular, Woollings et al. (2012) suggested these changes in the North Atlantic are driven by the changes in the ocean circulation, especially the Atlantic meridional overturning circulation. 
Fig. 9 Histograms of the standard deviations for a number of central jet $\left(48^{\circ}-51^{\circ} \mathrm{N}\right)$ days in each winter and $\mathbf{b}$ number of blocking days over Azores $\left(35^{\circ}-45^{\circ} \mathrm{N}, 20^{\circ}-50^{\circ} \mathrm{W}\right)$ in each winter for 1951-2005 from the all 40 members of the CESM1LE. The standard deviations are calculated in two different ways. The blue bars are for the interannual standard deviations calculated along time dimension for each ensemble member. On the other hand, the white bars with red edges are for the ensemble standard deviations calculated across the 40 ensemble members for each given year
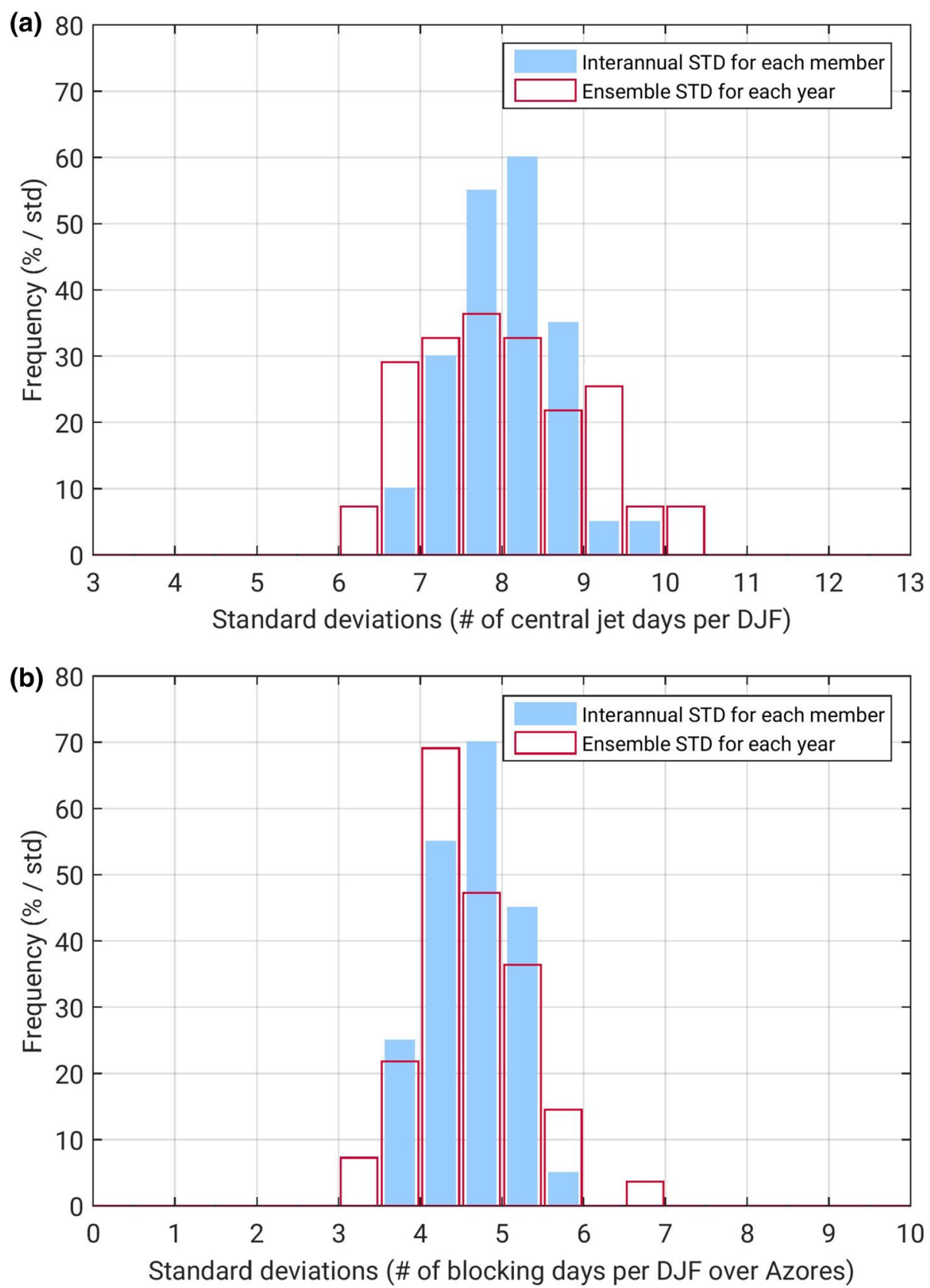

While we have primarily focused on the daily jet latitude in this study, the bias in the strength of the eddy-driven jet may impact the bias in the jet latitude. Previous studies suggested that the leading mode of eddy-driven jet changes from the wobbling of the latitude to the pulsing of the strength, if the jet is too strong and northerly (Barnes and Hartmann 2011; Davini and Cagnazzo 2013). When the jet is too strong, Rossby wave propagation tends to be trapped near the jet core, and thus Rossby wave breaking on either side of the jet becomes limited, which in turn results in limited latitudinal shifts of the jet (Woollings et al. 2018). The overly strong eddy-driven jet in CESM1LE could thus be a reason for the limited range of variability in jet latitude and the associated bias in blocking days.

The eddy-driven jet, blocking and circulation are the most fundamental components of the weather and climate 

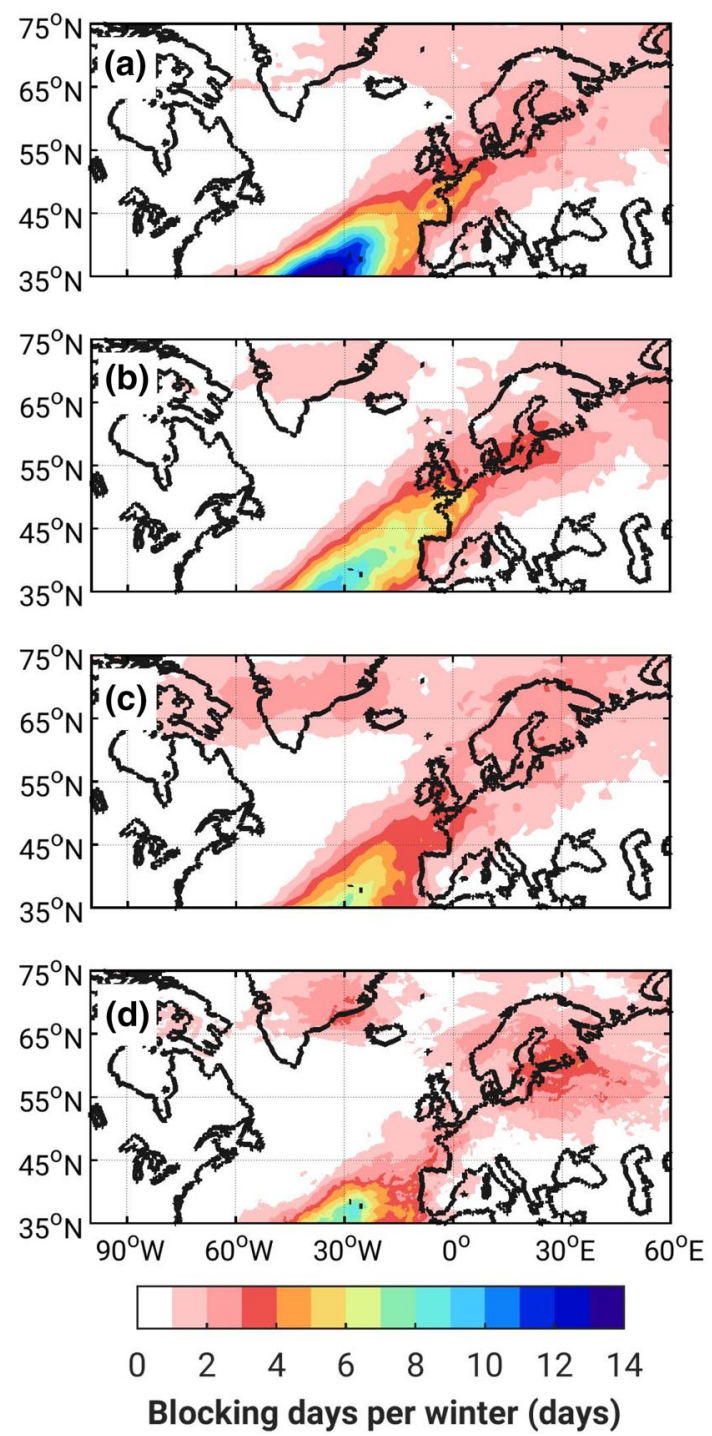

Fig. 10 Winter (December-February) mean number of blocking days from a $1^{\circ}$ coupled simulation of the CESM1LE ensemble member \#3 (1951-2005), b $1^{\circ}$ CAM5 atmosphere-only simulation with specified time-varying observed SST (1951-2005), c $1^{\circ}$ CAM5 atmosphere-only simulation with specified time-varying observed SST (1956-2010) and a better resolved stratosphere, so-called 46-level CAM from Richter et al. (2015), and d $0.25^{\circ}$ CAM5 atmosphere-only simulation with specified observed climatological SST (25 winters with different initial conditions on November 1st) from Smirnov et al. (2015)

in the North Atlantic sector. Thus, the model biases investigated in this study present a critical challenge in improving our dynamical understanding and the future projection in this region. Increased effort in understanding fundamental dynamics of the jet and wave breaking would be required to make significant progress in reducing these biases.
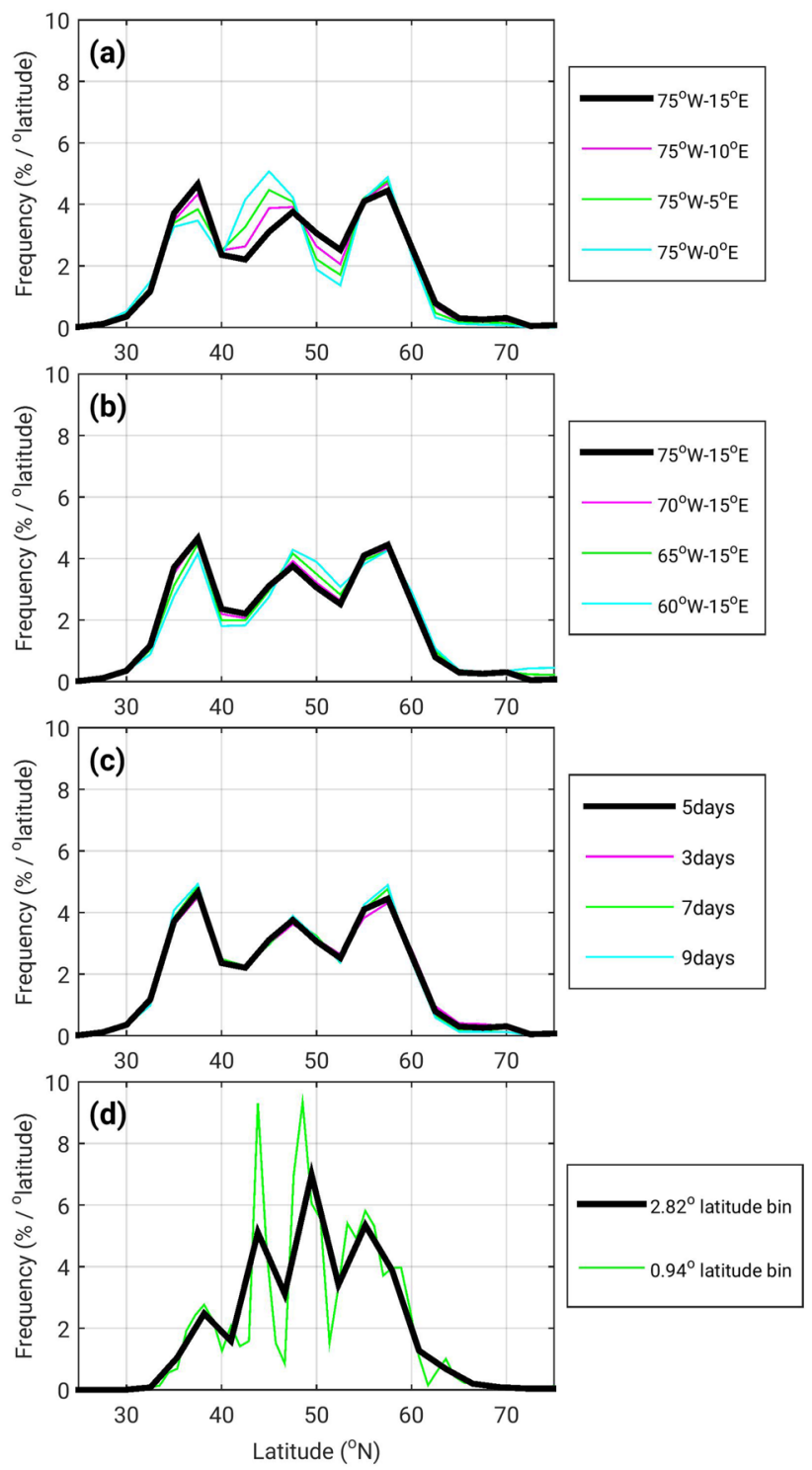

Fig. 11 The histograms of winter (December-February) daily jet latitude in the North Atlantic for 1951-2005 from a-c the NCEP-NCAR reanalysis and $\mathbf{d}$ the CESM1LE ensemble member \#11. The black lines are for the jet latitudes used in the main text, which are defined based on the daily $850 \mathrm{hPa}$ zonal wind averaged over $75^{\circ} \mathrm{W}-15^{\circ} \mathrm{E}$ and smoothed using 5-day moving window. Each panel shows the sensitivity of the jet latitude distribution when these parameters are changed one at a time, i.e., a the eastern limit of the zonal averaging range, $\mathbf{b}$ the western limit of the zonal averaging range, $\mathbf{c}$ the length of the temporal smoothing window, and $\mathbf{d}$ the bin size of the histogram

Acknowledgements Authors gratefully acknowledge support from the UCAR Significant Opportunities in Atmospheric Research and Science (SOARS) and WHOI Summer Student Fellowship programs. AC and CM were supported in part by the SOARS program, NSF Grant AGS1120459. In addition, the supports by the NSF AGS Climate and Largescale Dynamics program and OCE Physical Oceanography program (AGS-1355339) to Y-OK and HS, the DOE BER Regional and Global 
Climate Modeling program (DE-SC0014433) to Y-OK, and the NSF EaSM3 Sustainability Research Networks program (OCE-1419235) to HS are acknowledged. The authors are also grateful to Adam Phillips, Jadwiga Richter, and Clara Deser for making the various CESM1 simulations available and the two anonymous reviewers and editor Susanna Corti for the thorough and constructive comments.

Open Access This article is distributed under the terms of the Creative Commons Attribution 4.0 International License (http://creativecommons.org/licenses/by/4.0/), which permits unrestricted use, distribution, and reproduction in any medium, provided you give appropriate credit to the original author(s) and the source, provide a link to the Creative Commons license, and indicate if changes were made.

\section{Appendix: sensitivity on the definition of the jet latitude}

In this appendix, the sensitivity of the jet latitude distribution on the choice of the longitudinal range for zonal averaging and the size of the window for temporal smoothing for the definition of the daily jet as well as the bin size for the histogram of jet latitude are examined. As described in Sect. 2.4, the daily zonal wind at $850 \mathrm{hPa}$ is first averaged zonally for $75^{\circ} \mathrm{W}-15^{\circ} \mathrm{E}$ and temporally smoothed with a 5-day running mean. Then, the latitude of the maximum amplitude is identified as the jet latitude for each day. The histogram using this default definition is plotted as the black curve in each panel of the Fig. 11. Then, we changed only one of the parameters at a time to examine the sensitivity. First, the eastern limit of the zonal averaging range is varied between $0^{\circ}$ and $15^{\circ} \mathrm{E}$ (Fig. 11a). The three-peak distribution is found to be robust regardless of the change, while the amplitude of the central jet peak becomes gradually larger as the eastern limit moved westward, while the corresponding decrease is found at the southern jet peak. The sensitivity is much smaller for the next two tests (Fig. 11b, c), i.e., the changes in the western limit of the zonal averaging range and the size of the temporal smoothing window. Finally, the sensitivity to the bin size for the histogram of CESM1LE jet latitude is tested. In the main text, the bin size of $2.8272^{\circ}$ corresponding to the three latitude grids for each bin is used, so that the bin size can be comparable to that for the NCEP-NCAR reanalysis $\left(=2.5^{\circ}\right)$. In the Fig. 11d, an additional histogram (green curve) is plotted using a smaller bin size, which is the native latitude grid size of CESM1LE $\left(=0.9424^{\circ}\right)$. The three primary peaks and one additional southernmost peak are found to be robust features regardless of the bin size, although the northern jet peak is somewhat diffused. Overall, the jet latitude distribution is found to be rather insensitive to the exact definition.

\section{References}

Anstey JA, Davini P, Gray LJ, Woollings TJ, Butchart N, Cagnazzo C, Christiansen B, Hardiman SC, Osprey SM, Yang S (2013) Multi-model analysis of Northern Hemisphere winter blocking: model biases and the role of resolution. J Geophys Res Atmos 118:3956-3971. https://doi.org/10.1002/jgrd.50231

Barnes EA, Hartmann DL (2010) Influence of eddy-driven jet latitude on North Atlantic jet persistence and blocking frequency in CMIP3 integrations. Geophys Res Lett 37:L23802. https://doi. org/10.1029/2010GL045700

Barnes EA, Hartmann DL (2011) Rossby wave scales, propagation, and the variability of eddy-driven jets. J Atmos Sci 68:2893-2908. https://doi.org/10.1175/JAS-D-11-039.1

Barnes EA, Slingo J, Woollings T (2012) A methodology for the comparison of blocking climatologies across indices, models and climate scenarios. Clim Dyn 38:2467-2481. https://doi.org/10.1007/ s00382-011-1243-6

Barnston AG, Livezey RE (1987) Classification, seasonality and persistence of low-frequency atmospheric circulation patterns. Mon Weather Rev 115:1083-1126

Barriopedro D, García-Herrera R, Lupo AR, Hernández E (2006) A climatology of northern hemisphere blocking. J Clim 19:1042-1063. https://doi.org/10.1175/JCLI3678.1

Barriopedro D, García-Herrera R, Trigo RM (2010) Application of blocking diagnosis methods to General Circulation Models. Part I: a novel detection scheme. Clim Dyn 35:1373-1391. https://doi. org/10.1007/s00382-010-0767-5

Berckmans J, Woollings T, Demory M-E, Vidale P-L, Roberts M (2013) Atmospheric blocking in a high resolution climate model: influences of mean state, orography and eddy forcing. Atmos Sci Lett 14:34-40. https://doi.org/10.1002/as12.412

Branstator G, Selten F (2009) "Modes of variability" and climate change. J Clim 22:2639-2658. https://doi.org/10.1175/2008J CLI2517.1

Bueh C, Nakamura H (2007) Scandinavian pattern and its climatic impact. Q J R Meteorol Soc 133:2117-2131. https://doi. org/10.1002/qj.173

Compo GP, Whitaker JS, Sardeshmukh PD (2006) Feasibility of a 100 year reanalysis using only surface pressure data. Bull Am Meteorol Soc 87:175-190

Compo GP et al (2011) The twentieth century reanalysis project. Q J R Meteorol Soc 137:1-28

D'Andrea F et al (1998) Northern Hemisphere atmospheric blocking as simulated by 15 atmospheric general circulation models in the period 1979-1988. Clim Dyn 14:385-407. https://doi. org/10.1007/s003820050230

Danabasoglu G, Bates SC, Briegleb BP, Jayne SR, Jochum M, Large WG, Peacock S, Yeager SG (2012) The CCSM4 ocean component. J Clim 25:1361-1389. https://doi.org/10.1175/ JCLI-D-11-00091.1

Davini P, Cagnazzo C (2013) On the misinterpretation of the North Atlantic Oscillation in CMIP5 models. Clim Dyn 43:14971511. https://doi.org/10.1007/s00382-013-1970-y

Davini P, D'Andrea F (2016) Northern hemisphere atmosphere blocking representation in global climate models: twenty years of improvements? J Clim 29:8823-8840. https://doi. org/10.1175/JCLI-D-16-0242.1

Davini P, Cagnazzo C, Neale R, Tribbia J (2012) Coupling between Greenland blocking and the North Atlantic Oscillation pattern. Geophys Res Lett 39:L14701. https://doi. org/10.1029/2012GL052315

Doblas-Reyes FJ, Déqué M, Valero F, Stephenson DB (1998) North Atlantic wintertime intraseasonal variability and its sensitivity to GCM horizontal resolution. Tellus A 50:573-595 
Dunn-Sigouin E, Son S-W (2013) Northern hemisphere blocking frequency and duration in the CMIP5 models. J Geophys Res Atmos 118:1179-1188. https://doi.org/10.1002/jgrd.50143

Dunn-Sigouin E, Son S-W, Lin H (2013) Evaluation of northern hemisphere blocking climatology in the global environment multiscale model. Mon Weather Rev 141:707-727. https://doi. org/10.1175/MWR-D-12-00134.1

Gent PR et al (2011) The community climate system model version 4. J Clim 24:4973-4991

Holland MM, Bailey DA, Briegleb BP, Light B, Hunke E (2012) Improved sea ice shortwave radiation physics in CCSM4: the impact of melt ponds and aerosols on Arctic sea ice. J Clim 25:1413-1430

Hoskins BJ, Ambrizzi T (1993) Rossby wave propagation on a realistic longitudinally varying flow. J Atmos Sci 75:1825-1830

Hoskins BJ, James IN, White GH (1983) The shape, propagation and mean-flow interaction of large-scale weather systems. J Atmos Sci 40:1595-1612

Hurrell JW (1995) Decadal trends in the North Atlantic oscillation: regional temperatures and precipitation. Science 269:676-679

Jung T et al (2012) High-resolution global climate simulations with the ECMWF model in project Athena: experimental design, model climate, and seasonal forecast skill. J Clim 25:3155-3172. https:// doi.org/10.1175/JCLI-D-11-00265.1

Kalnay E et al (1996) The NCEP/NCAR 40-year reanalysis project. Bull Am Meteorol Soc 77:437-471

Kay JE et al (2015) The community earth system model (CESM) large ensemble project: a community resource for studying climate change in the presence of internal climate variability. Bull Am Meteorol Soc 96:1333-1349. https://doi.org/10.1175/ BAMS-D-13-00255.1

Kistler R et al (2001) The NCEP-NCAR 50-year reanalysis: monthly means CD-ROM and documentation. Bull Am Meteor Soc $82: 247-267$

Lamarque JF et al (2010) Historical (1850-2000) gridded anthropogenic and biomass burning emissions of reactive gases and aerosols: methodology and application. Atmos Chem Phys 10:70177039. https://doi.org/10.5194/acp-10-7017-2010

Lawrence DM et al. (2012) The CCSM4 land simulation, 1850-2005: assessment of surface climate and new capabilities. J Clim 25:2240-2260, https://doi.org/10.1175/JCLI-D-11-00103.1

Lejanäs H, Økland H (1983) Characteristics of Northern hemisphere blocking as determined from a long series of observational data. Tellus 35:350-362

Lim Y-K (2015) The East Atlantic/West Russia (EA/WR) teleconnection in the North Atlantic: climate impact and relation to Rossby wave propagation. Clim Dyn 44:3211-3222. https://doi. org/10.1007/s00382-014-2381-4

Lu J, Vecchi GA, Reichler T (2007) Expansion of the Hadley cell under global warming. Geophys Res Lett 34:L06805-L06805. https:// doi.org/10.1029/2006GL028443

Masato G, Hoskins BJ, Woollings T (2013) Winter and summer northern hemisphere blocking in CMIP5 models. J Clim 26:7044-7059. https://doi.org/10.1175/JCLI-D-12-00466.1

Matsueda M, Mizuta R, Kusunoki S (2009) Future change in wintertime atmospheric blocking simulated using a 20-km-mesh atmospheric global circulation model. J Geophys Res 114:D12114D12110. https://doi.org/10.1029/2009JD011919

McIntyre ME, Palmer TN (1983) Breaking planetary waves in the stratosphere. Nature 305:593-600

Meehl GA, Convey C, Taylor KE, Delworth T, Stouffer RJ, Latif M, McAvaney B, Mitchell JFB (2007) The WCRP CMIP3 multimodel dataset: a new era in climate change research. Bull Am Meteorol Soc 88:1383-1894. https://doi.org/10.1175/BAMS-88-9-1383
Meinshausen M et al (2011) The RCP greenhouse gas concentrations and their extension from 1765 to 2300 . Clim Change 109:213241. https://doi.org/10.1007/s10584-011-0156-z

Michel C, Rivière G (2011) The link between Rossby wave breakings and weather regime transitions. J Atmos Sci 68:1730-1748. https://doi.org/10.1175/2011JAS3635.1

Neale RB, Richter J, Park S, Lauritzen PH, Vavrus SJ, Rasch PJ, Zhang M (2013) The mean climate of the community atmosphere model (CAM4) in forced SST and fully coupled experiments. J Clim 26:5150-5168. https://doi.org/10.1175/JCLI-D-12-00236.1

Park S, Bretherton CS, Rasch PJ (2014) Integrating cloud processes in the community atmosphere model, version 5. J Clim 27:68216856. https://doi.org/10.1175/JCLI-D-14-00087.1

Pelly JL, Hoskins BJ (2003) A new perspective on blocking. J Atmos Sci 60:743-755

Pinto JG, Ulbrich U, Leckebusch GC, Spangehl T, Reyers M, Zacharias $\mathrm{S}$ (2007) Changes in storm track and cyclone activity in three SRES ensemble experiments with the ECHAM5/MPI-OM1 GCM. Clim Dyn 29:195-210. https://doi.org/10.1007/s00382-007-0230-4

Pithan F, Shepherd TG, Zappa G, Sandu I (2016) Climate model biases in jet streams, blocking and storm tracks resulting from missing orographic drag. Geophys Res Lett 43:7231-7240. https://doi. org/10.1002/2016GL069551

Rex DF (1950) Blocking action in the middle troposphere and its effect upon regional climate. Part I: an aerological study of blocking action. Tellus 2:196-211

Richter JH, Deser C, Sun L (2015) Effects of stratospheric variability on El Niño teleconnections. Environ Res Lett 10:1-10. https://doi. org/10.1088/1748-9326/10/12/124021

Scaife AA, Woollings T, Knight J, Martin G, Hinton T (2010) Atmospheric blocking and mean biases in climate models. J Clim 23:6143-6152. https://doi.org/10.1175/2010JCLI3728.1

Scaife AA et al (2011) Improved Atlantic winter blocking in a climate model. Geophys Res Lett 38:L23703. https://doi. org/10.1029/2011GL049573

Scherrer S, Croci-Maspoli M, Schwierz C, Appenzeller C (2006) Twodimensional indices of atmospheric blocking and their statistical relationship with winter climate patterns in the Euro-Atlantic region. Int J Climatol 26:233-249

Schiemann R, Demory M, Shaffrey L, Strachan J, Vidale P, Mizielinski M, Roberts M, Matsueda M, Wehner M, Jung T (2017) The resolution sensitivity of Northern Hemisphere blocking in four 25-km atmospheric global circulation models. J Clim 30:337-358. https://doi.org/10.1175/JCLI-D-16-0100.1

Smirnov D, Newman M, Alexander MA, Kwon Y-O, Frankignoul C (2015) Investigating the local atmospheric response to a realistic shift in the Oyashio sea surface temperature front. J Clim 28:1126-1147. https://doi.org/10.1175/JCLI-D-14-00285.1

Taylor KE, Stouffer RJ, Meehl GA (2012) An overview of CMIP5 and the experiment design. Bull Am Meteorol Soc 93(4):485-498

Tibaldi S, Molteni F (1990) On the operational predictability of blocking. Tellus 42A:343-365

Ulbrich U, Pinto JG, Kupfer H, Leckebusch GC, Spangehl T, Reyers M (2008) Changing Northern hemisphere storm tracks in an ensemble of IPCC climate change simulations. J Clim 21:1669-1679. https://doi.org/10.1175/2007JCLI1992.1

Woollings T, Hoskins B, Blackburn M, Berrisford P (2008) A new Rossby wave-breaking interpretation of the north atlantic oscillation. J Atmos Sci 65:609-626. https://doi. org/10.1175/2007JAS2347.1

Woollings T, Hannachi A, Hoskins B (2010) Variability of the North Atlantic eddy-driven jet stream. Q J R Meteorol Soc 136:856-868. https://doi.org/10.1002/qj.625

Woollings T, Gregory JM, Pinto JG, Reyers M, Brayshaw DJ (2012) Response of the North Atlantic storm track to climate change 
shaped by ocean-atmosphere coupling. Nat Geosci 5:1-5. https:// doi.org/10.1038/ngeo1438

Woollings T, Barnes E, Hoskins B, Kwon Y-O, Lee RW, Li C, Madonna E, McGraw M, Parker T, Rodrigues R, Spensberger C, Williams K (2018) Daily to decadal modulation of jet variability. J Clim. https://doi.org/10.1175/JCLI-D-17-0286.1
Yin JH (2005) A consistent poleward shift of the storm tracks in simulations of 21 st century climate. Geophys Res Lett $32 \mathrm{https} / /$ doi. org/10.1029/2005GL023684 